\title{
PDA (Posterior Descending Artery) \& Coronary Dominance-A MDCT Coronary Angiographic Analysis of Anatomic Variations and Clinical Importance
}

\author{
Sushma Tomar', Punita Manik', P K Sharma ${ }^{3}$, Manoj Kumar ${ }^{4}$ \\ 'Assistant Professor, Department of Anatomy, King George's Medical University UP, Lucknow, ${ }^{2}$ Professor, Department of Anatomy, King George's Medical \\ University UP, Lucknow, ${ }^{3}$ Professor \& Head, Department of Anatomy, Era Lucknow Medical College, Lucknow, ${ }^{4}$ Professor, Department of Radiodiagnosis, \\ King George's Medical University UP, Lucknow.
}

\section{Abstract}

Introduction: There is considerable variation in the arterial supply of diaphragmatic surface of the heart. Diaphragmatic myocardial infarction is one of the more common consequences of coronary artery disease. The aim of this study was to assess the incidence of anatomic variants of origin and termination of Posterior Descending Artery (PDA) and to determine the type of coronary dominance in North Indian population. Subjects and Methods: This prospective study was carried out on 50 routine subjects of different age groups who came to the Department of Radiodiagnosis, King George's Medical University UP, Lucknow in the year 2010- 2011 with known or suspected coronary artery disease. All the cases were investigated on a 64 slice Multidetector Computed Tomographic (MDCT) scanner, using retrospective Electrocardiographic gating. Endeavour was made to determine the incidence of sites of origin and termination of PDA as well as to determine the type of coronary dominance. Results: PDA arose from Right Coronary Artery (RCA) in 39 (78\%) cases and from Left Circumflex (LCx) artery in 11(22\%) cases. The PDA was found to terminate in the upper 1/4 of Posterior Inter-Ventricular Groove (PIVG) in $18(36 \%)$ cases, in upper $1 / 2$ of PIVG in $19(38 \%)$ cases, in upper $3 / 4$ of PIVG in $10(20 \%)$ cases and at the apex of the heart in $1(2 \%)$ case. None of the female had termination of PDA at the apex. Termination of PDA could not be determined in $2(4 \%)$ cases. Right dominance was seen in $36(72 \%)$ cases, Left dominance in $11(22 \%)$ cases. and Co-dominance in $3(6 \%)$ cases. Conclusion: Posterior descending artery most commonly terminated after traversing the upper half of posterior inter-ventricular groove. The incidence of left coronary dominance was more in females, it was approximately twice the incidence found in males. Co-dominance was observed only in male subjects.

Keywords: Coronary Angiography, Coronary Dominance, Multidetector Computed Tomography, Posterior Descending Artery.

Corresponding Author: Dr. Sushma Tomar, Flat No- 406, Tulip-A, Omaxe Residency-1,Sector-7, Gomti Nagar Extension, Sultanpur Road, Near Arjunganj, Lucknow. 226010

Received: November 2018

Accepted: November 2018

\section{Introduction}

There is a wide range of variations within normal anatomic distribution of Posterior descending artery (PDA). PDA arises from Right Coronary Artery (RCA) in right dominant and co-dominant hearts, while it arises from Left Circumflex (LCx) artery in left dominant hearts. PDA supplies inferior wall of heart and inferior third of the interventricular septum. The artery that supplies the PDA and a posterolateral branch determines the coronary dominance. ${ }^{[1]}$ PDA is also known as Posterior Inter-Ventricular Artery (PIVA). The site of origin of PDA is variable. In approximately $70 \%$ individuals, it arises from RCA near the crux of the heart and ends by anastomosing with the Anterior Inter-Ventricular Artery (AIVA) [Left Anterior Descending (LAD) artery] of Left Coronary Artery (LCA). In approximately $10 \%$ individuals, it arises either as a branch or continuation of LCx artery. The PDA extends along the posterior inter-ventricular groove (PIVG), from the crux of the heart toward the apex. PDA passes forward along the interventricular sulcus for a variable distance toward the apex of the heart. When the PDA has a premature takeoff and then courses toward the cardiac apex along the diaphragmatic surface of the right ventricle, the variant is called early takeoff of the PDA.

The concept of RCA or LCA preponderance was first proposed by Schlesinger M.J. in 1940. The term 'dominant' coronary artery was introduced by Schlesinger who used it to indicate the areas of heart supplied by each artery. Coronary dominance is based on the arterial supply to the diaphragmatic surface of heart by either right or left coronary artery. ${ }^{[2]}$ The dominant coronary artery is that which gives the posterior interventricular branch, traversing the posterior interventricular sulcus and supplying the posterior part of the ventricular septum and often part of the 


\section{Tamar et al; PDA d Caranary Daminance}

posterolateral wall of the left ventricle as well. ${ }^{[3]}$

According to Dr. Matt A. Morgan coronary artery "dominance" is defined in terms of which coronary artery gives origin to the PDA and the Posterior Left Ventricular Branches (PLVBs). Most persons (approximately 89.1\%) have a "right-dominant" system, which means that the RCA supplies these arteries. Approximately $8.4 \%$ of persons have a "left-dominant" system, which means that the LCx artery supplies these arteries. Approximately $2.5 \%$ persons have "co-dominant" system in which the RCA gives origin to the PDA and the LCx artery gives origin to the PLVBs. ${ }^{[4]}$

The artery that supplies the posterior descending artery (PDA) and the posterolateral Branch (PLB) determines the coronary dominance. If the PDA and PLB arise from the RCA, then the system is said to be right dominant. If the PDA and PLB arise from the LCx artery, then the system is said to be left dominant. If the PDA comes from the RCA and the PLB comes from the LCX artery, the system is codominant. $^{[5]}$

Branches of both RCA and LCx arteries run in or near the PIVG in balanced pattern (co-dominance) of coronary distribution. ${ }^{[6]}$

Dominance has important implications in myocardial ischaemia and infarction, imaging of the coronary arteries (CTCA and invasive coronary angiography) and the planning for coronary artery bypass grafting. ${ }^{[7]}$

\section{Subjects and Methods}

\section{Materials}

In this study, digital copies of CT coronary angiograms of 50 subjects of both sex and different age groups [32 males (14-75 years), 18 females (12-70 years); mean age $51.36 \pm 14.07$ years, age range $12-75$ years] were analyzed after taking due permission from Institutional Ethical Committee.

\section{Method}

This was an observational study. The sites of origin and termination of PDA were observed. Coronary angiograms were also observed for origin of PLVB. Coronary Angiography (CA) was done on patients came to the Department of Radiodiagnosis, King George's Medical University UP, Lucknow in the year 2010- 2011 with known or suspected coronary artery disease.

\section{Inclusion criteria}

Patients presenting with symptoms and signs of cardiovascular diseases e.g. Chest pain and Dyspnoea.

\section{Exclusion criteria}

(1) Lack of consent.

(2) Renal insufficiency (High urea / creatinine level).

(3) Allergy to contrast agent.

(4) Contraindication to radiation exposure (e.g.pregnancy). I

(5) Uncontrolled Heart rate.

(6) Atrial fibrillation, frequent atrial or ventricular ectopics ( $>1 /$ minute).

(7) Unable to hold breath for 20 seconds.

CA was performed on 64 Slice Multidetector Computed Tomographic (MDCT) scanner (BRILLIANSTMCT,
Version 2.45.22042, manufactured by Philips) which is installed in the department of Radiodiagnosis, King George's Medical University (KGMU), Lucknow, Uttar Pradesh (U.P.), India. Retrospective Electrocardiographically gated imaging was performed (Technical parameters are given in Table 1).

Table 1: Technical Parameters applied in Computed Tomographic Coronary Angiographic (CTCA) images acquisition.

\begin{tabular}{|c|c|}
\hline \multicolumn{2}{|c|}{$\begin{array}{l}\text { DEVICE - BRILLIANSTMCT, Version 2.45.22042, manufactured } \\
\text { by Philips }\end{array}$} \\
\hline Slices/collimation & $64 / 0.625 \mathrm{~mm}$ \\
\hline $\begin{array}{l}\text { Effective temporal resolution (with } \\
180^{\circ} \text { algorithm) }\end{array}$ & $165 \mathrm{~ms}$ \\
\hline Tube current & $800 \mathrm{mAs}$ \\
\hline Pitch & 0.2 \\
\hline Tube voltage & $120 \mathrm{kV}$ \\
\hline Tube rotation time & $400 \mathrm{~ms}$ \\
\hline Section thickness & $0.9 \mathrm{~mm}$ \\
\hline Reconstruction Increment & $0.45 \mathrm{~mm}$ \\
\hline Field of view (FOV) & $220 \mathrm{~mm}$ \\
\hline ECG gating & Retrospective \\
\hline Isotropic voxel resolution & $0.4 \times 0.4 \times 0.4 \mathrm{~mm}$. \\
\hline Scanning time & $10-12$ seconds \\
\hline
\end{tabular}

\section{Pre-procedure precautions}

- The subjects were enquired, to rule out the presence of any drug allergy to avoid the occurrence of any untoward anaphylactic reaction during the procedure.

- Two days prior to the procedure the subjects were advised to avoid the intake of fatty food.

- They were advised to drink only water just prior to the procedure.

- Blood urea and creatinine levels were evaluated.

\section{Procedure}

The subjects were laid supine. Their heart rate was stabilized with an oral dose of 50-100 mg Metoprolol one hour before the scan. If heart rate was not stabilized with an oral dose, then intravenous (IV) Metoprolol was given. Electrocardiogram (ECG) and pulse rate were monitored half an hour prior to the procedure. The subjects were counseled to reduce their anxiety.

The subjects were connected to a cardiac monitor. For venous access, an upper extremity vein (antecubital vein) and a 20-gauge intravenous canula was used. $80-85 \mathrm{ml}$ of non-ionic contrast Iohexol (Omnipaque, GE, GE Healthcare Ireland, Cork) containing iodine concentration of 350 $\mathrm{mgI} / \mathrm{ml}$, injected with a flow rate of $5.5 \mathrm{ml} / \mathrm{sec}$, followed by a $20 \mathrm{ml}$ saline flush at a rate of $4 \mathrm{ml} / \mathrm{sec}$ with a pressure injector (PSI-325). The scan timing was determined with automated bolus tracking technique by placing the region of interest over mid ascending aorta and setting the trigger threshold to 180 Hounsfield $(\mathrm{Hu})$. The subjects were asked to lie still on the "scanning bed" for a period of 5-10 minutes. The instruction was given to the subjects to maintain an inspiratory breath hold during which $\mathrm{CT}$ data and ECG tracings were taken. CTCA was performed 5 seconds after aortic peak density. Scanning coverage was from the level of carina to the bottom of the heart. Raw spiral CT data of coronary arteries were reconstructed in various phases of cardiac cycle on a work station (Brilliance 
64 version 4.5) to obtain images with the highest quality (without motion artefact).Reconstruction performed at $75 \%$ of R-R interval was found to be optimal for image analysis in most of the subjects. In some, if heart rate could not be stabilized properly, then reconstructions were performed at $45 \%$ of R-R interval. The images generated were reconstructed and viewed utilizing a separate workstation which enabled generation of the coronary arteries in the standard and in various other anatomical planes as and when required and were interpreted with the help of a cardiac radiologist. Subjects with previous bypass surgery and also those with suboptimal study due to breath hold artefacts were excluded.

All images were reviewed first in axial projection and then with post processing tools such as Multiplanar Reconstruction (MPR), Curved Planar Reformation (CPR), thin-slab Maximum Intensity Projection (MIP), and Volume-Rendering Technique (VRT) with transparent background display. MIPs were obtained using various thicknesses (5-30 mm). Volume-rendered (VR) images were also obtained using various orientations.

CTCA images were observed for the origin and termination of PDA and origin of PLVB. The statistical analysis was performed by using software SPSS (Statistical Package for Social Sciences) version 15.0. The values were represented in Number (\%) and Mean \pm Standard Deviation (SD).

\section{Results}

Table 2: Gender-wise Comparison of frequency of Site of Origin of PDA

\begin{tabular}{|c|c|c|c|}
\hline Site of origin & $\begin{array}{l}\text { Male } \\
(\mathrm{Nm}=32)\end{array}$ & $\begin{array}{l}\text { Female } \\
(\mathrm{Nf}=18)\end{array}$ & $\begin{array}{l}\text { Total } \\
(\mathrm{Nt}=50)\end{array}$ \\
\hline $\begin{array}{l}\text { Right Coronary } \\
\text { Artery (RCA) }\end{array}$ & $27(84.38)$ & $12(66.67)$ & $39(78)$ \\
\hline $\begin{array}{l}\text { Left circumflex } \\
(\text { LCx) Artery }\end{array}$ & $5(15.63)$ & $6(33.33)$ & $11(22.0)$ \\
\hline
\end{tabular}
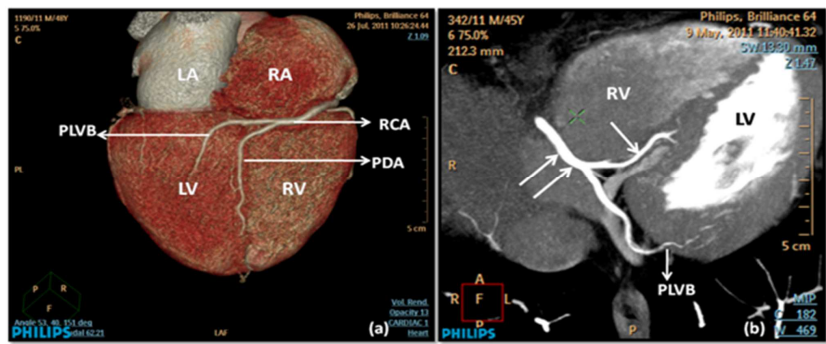

Figure 1: MDCT Images showing Origin of PDA from RCA \& Right Dominance (a) 3D VR Image, (b) Axial MIP Image [PDA (single arrow), RCA (double arrow)] RA- Right Atrium, RV- Right Ventricle, LA- Left Atrium, LV- Left Ventricle, RCA- Right Coronary Artery, PDA- Posterior Descending Artery, PLVB- Posterior Left Ventricular Branch

PDA arose from RCA in $39(78 \%)$ cases [27 (84.38\%) males and $12(66.67 \%)$ females] [Figure $1 \mathrm{a} \& \mathrm{~b}$, Table 2]. PDA arose from LCX artery in $11(22 \%)$ cases [5 (15.63\%) males and $6(33.33 \%)$ females] [Figure 2 a $\&$ b, Table 2]. The PDA was found to terminate in the upper $1 / 4$ of posterior inter-ventricular groove (PIVG) in 18 (36\%) cases
[10(31.25\%) males and $8(44.44 \%)$ females], in upper $1 / 2$ of PIVG in $19(38 \%)$ cases [12 (37. 5\%) males and 7 (38.89\%) females], in upper $3 / 4$ of PIVG in $10(20 \%)$ cases [7 $(21.88 \%)$ males and $3(16.67 \%)$ females] and at the apex of the heart in $1(2 \%)$ case, a male $(3.13 \%)$. None of the female had termination of PDA at the apex. Termination of PDA could not be determined in $2(4 \%)$ cases [2(6.25\%) males] because of suboptimal study [Figure $3 \mathrm{a}, \mathrm{b}, \mathrm{c} \& \mathrm{~d}$, Table 3].
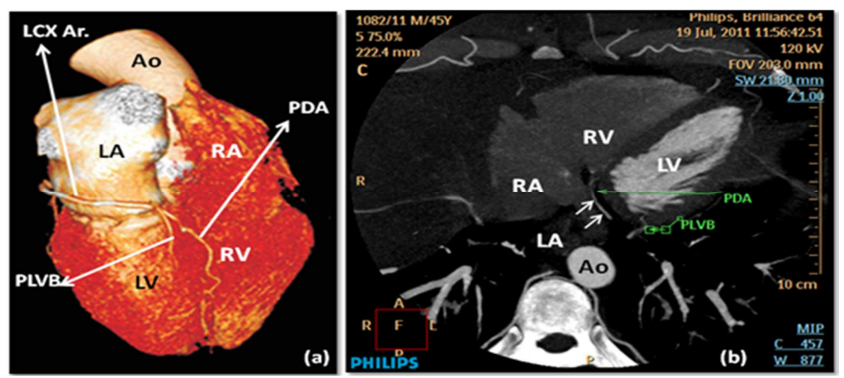

Figure 2: MDCT Images showing Origin of PDA from LCX Ar. \& Left Dominance (a) 3D VR Image, (b) Axial MIP Image [(LCX Ar. (double arrow)]. RA- Right Atrium, RV- Right Ventricle, LA- Left Atrium, LV- Left Ventricle, RCA- Right Coronary Artery, PDA- Posterior Descending Artery, , PLVBPosterior Left Ventricular Branch, LCx Ar.- Left Circumflex Artery Ao- Aorta

Table 3: Gender wise termination of PDA with reference to the length of Posterior Inter-Ventricular Groove (PIVG)

\begin{tabular}{|l|l|l|l|}
\hline $\begin{array}{l}\text { Site of } \\
\text { termination of } \\
\text { PDA }\end{array}$ & $\begin{array}{l}\text { Male } \\
(\mathbf{N m = 3 2})\end{array}$ & $\begin{array}{l}\text { Female } \\
(\mathbf{N f = 1 8})\end{array}$ & $\begin{array}{l}\text { Total } \\
(\mathbf{N t = 5 0 )}\end{array}$ \\
\hline $\begin{array}{l}\text { Upper } 1 / 4 \text { of } \\
\text { PIVG }\end{array}$ & $10(31.25)$ & $8(44.44)$ & $18(36)$ \\
\hline $\begin{array}{l}\text { Upper 1/2 of } \\
\text { PIVG }\end{array}$ & $12(37.50)$ & $7(38.89)$ & $19(38)$ \\
\hline $\begin{array}{l}\text { Upper 3/4 of } \\
\text { PIVG }\end{array}$ & $7(21.88)$ & $3(16.67)$ & $10(20)$ \\
\hline Cardiac apex & $1(3.13)$ & 0 & $1(2)$ \\
\hline Not determined & $2(6.25)$ & 0 & $2(4)$ \\
\hline
\end{tabular}
subjects

Figures in parentheses represent percentage. $\chi^{2}=2.407$; $\mathrm{p}=0.661$

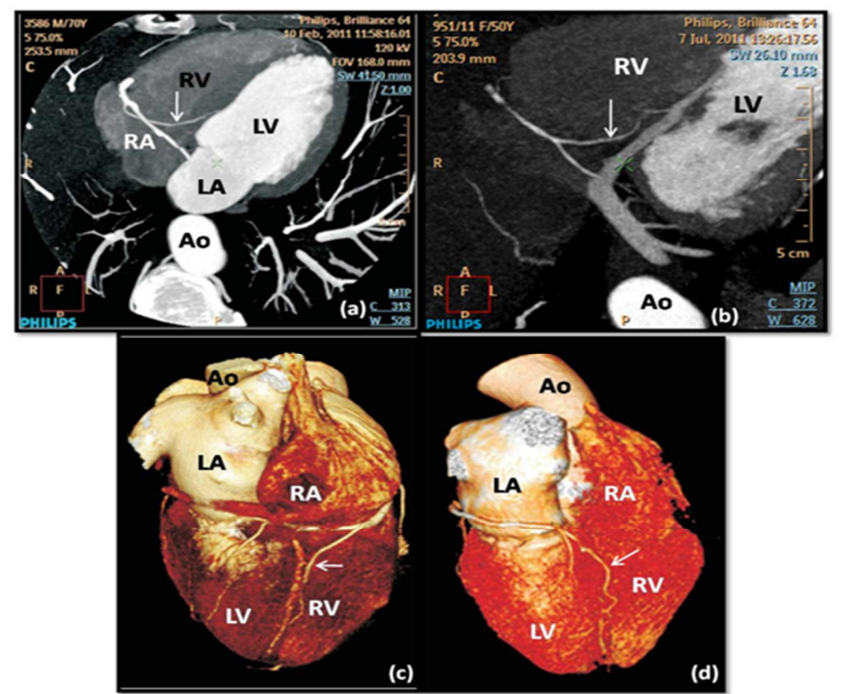

Figure 3: MDCT Images showing Termination of PDA (a) Axial MIP Image showing termination in upper 1/4 of PIVG, 


\section{Tamar et al; PDA d Caranary Daminance}

(b) Axial MIP Image showing termination in upper 1/2 of PIVG, (c) 3D VR Image showing termination in upper 3/4 of PIVG (d) 3D VR Image showing termination at cardiac apex [PDA(arrow)]. RA- Right Atrium, RV- Right Ventricle, LALeft Atrium, LV- Left Ventricle, Ao- Aorta

In the present study, the coronary dominance pattern results were: Right Dominance in $36(72 \%)$ cases [24 (75\%) males and $12(66.67 \%)$ females] [Figure 1a\&b], Left Dominance in $11(22 \%)$ cases [5 $(15.63 \%)$ males and $6(33.33 \%)$ females] [Figure 2a\&b] and Co-dominance in $3(6 \%)$ cases [3(9.38\%) males][Figure 4]. None of the female had co-dominance [Table 4].

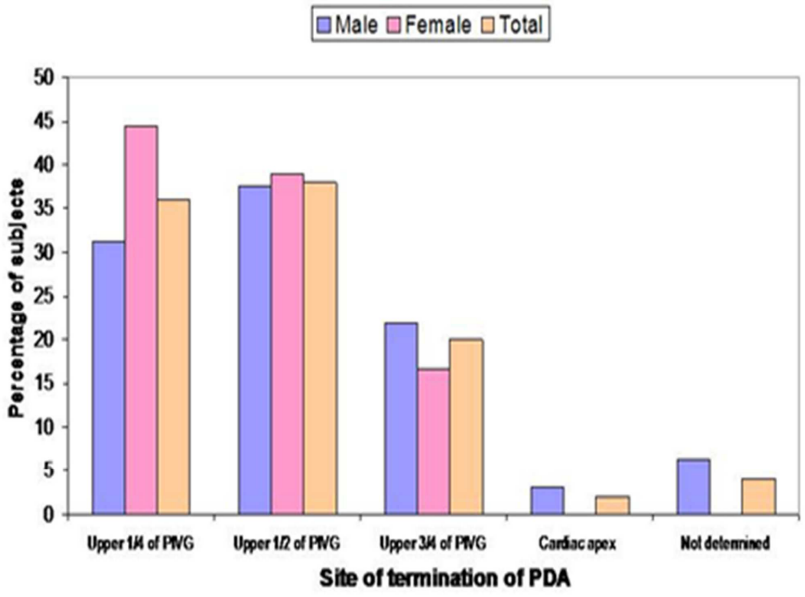

Graph 1: Bar Diagram showing Frequency of Termination of PDA in PIVG (PDA- Posterior Descending Artery, PIVGPosterior Interventriucular Groove)

Table 4: Gender-wise Frequency of coronary dominance

\begin{tabular}{|l|l|l|c|}
\hline $\begin{array}{l}\text { Dominance } \\
\text { pattern }\end{array}$ & Male(Nm=32) & Female(Nf=18) & Total(Nt=50) \\
\hline $\begin{array}{l}\text { Right } \\
\text { Dominance }\end{array}$ & $24(75)$ & $12(66.67)$ & $36(72 \%)$ \\
\hline $\begin{array}{l}\text { Left } \\
\text { Dominance }\end{array}$ & $5(15.63)$ & $6(33.33)$ & $11(22 \%)$ \\
\hline $\begin{array}{l}\text { Co- } \\
\text { dominance }\end{array}$ & $3(9.38)$ & 0 & $3(6 \%)$ \\
\hline
\end{tabular}

Nm-Total number of males, Nf-Total number of females, Nt-Total number of study subjects

Figures in parentheses represent percentage.

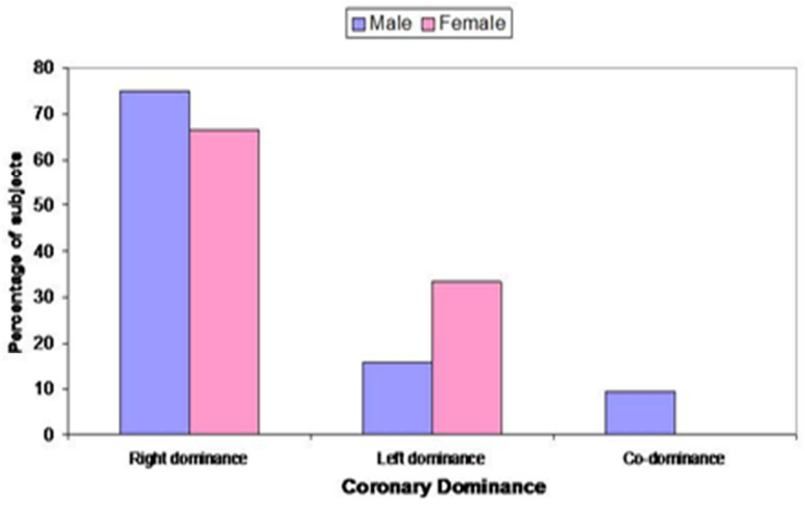

Graph 2: Bar Diagram showing gender-wise frequency of Coronary Dominance

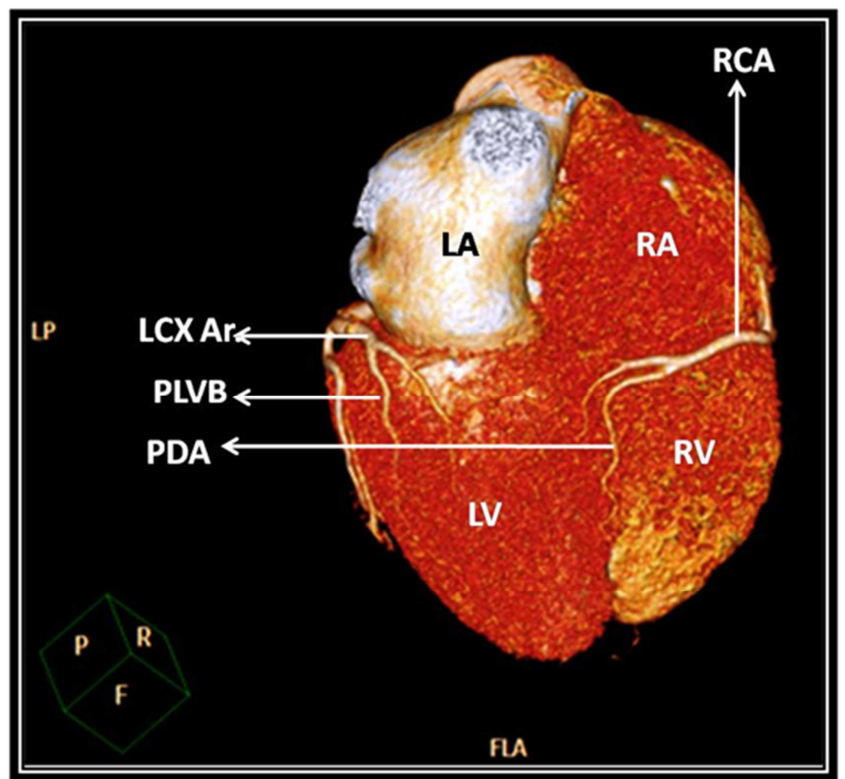

Figure 4: 3D VR Image showing co-dominance RA- Right Atrium, RV- Right Ventricle, LA- Left Atrium, LV- Left Ventricle, RCA- Right Coronary Artery, PDA- Posterior Descending Artery, PLVB- Posterior Left Ventricular Branch, LCx Ar.- Left Circumflex Artery

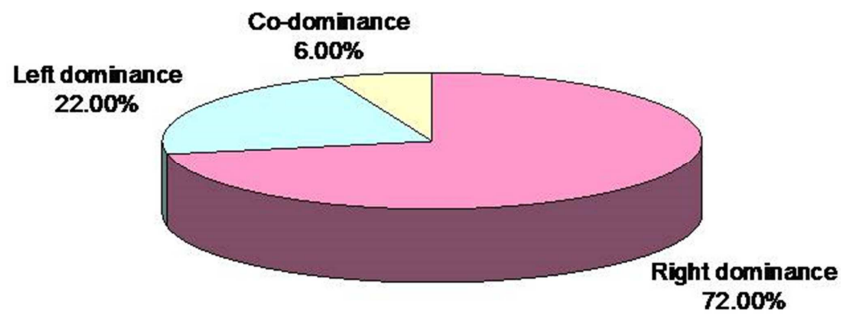

Graph 3: Pie Diagram showing percentage distribution of Coronary Dominance pattern

\section{Discussion}

Diaphragmatic myocardial infarction is one of the more common consequences of coronary artery disease. It can occur as a result of interruption of the blood supply to the posterior diaphragmatic portion of the inter-ventricular septum and/or the diaphragmatic surface of left ventricle. There is considerable variation in the arterial supply of this important region of the heart. A thorough understanding of these anatomic variations is required for proper interpretation of coronary angiograms. Understanding these variations is essential in diagnosing obstructions in these arteries and planning surgical therapy.

PDA, which is one of the most important branches of the RCA, supplies posterior diaphragmatic portion of the interventricular septum. The David C. Levin and Harold A. Baltaxe found significant anatomic variations in the origin, course or distribution of PDA in 23 per cent of a series of 200 patients. They found double posterior descending branches, early origin of the PDA and partial supply of the diaphragmatic portion of the septum by acute marginal or posterior right ventricular branches. They found double PDA in $6 \%$ cases and early origin of PDA in $5 \%$ cases. The preponderant or "dominant" artery is the one which supplies 
the posterior diaphragmatic portion of the inter-ventricular septum and the diaphragmatic surface of the left ventricle. In right dominant hearts, PDA arises from the RCA at or shortly before the crux. After passing the crux, the dominant RCA terminates by giving rise to one or more large Posterior Left Ventricular (PLV) arteries. These arteries are the main source of blood to the diaphragmatic surface of the left ventricle. In left dominant hearts, LCX artery passes around the left atrio-ventricular sulcus and gives PLV arteries. It then turns towards the apex of the heart as PDA. In codominant hearts, RCA reaches the crux of the heart where it turns towards the apex and continued as PDA. In these cases, PLV arteries originate from distal portion of LCX artery. ${ }^{[8]}$

The concept of coronary dominance is reflected by considerable variation in the blood supply to the inferior and posterior portion of the left ventricular wall. ${ }^{[9]}$ If the circumflex branch of the left coronary artery terminates in the posterior inter-ventricular sulcus, then the heart is left dominant. If the posterior septum is vascularised either by descending branches from both the RCA and the LCx arteries, or by a network of small branches from these two passing obliquely, so that there is no posterior interventricular branch. In such hearts the circulation is said to be 'balanced', as the posterior inter-ventricular branch is either bilateral or absent. ${ }^{[10]}$

In the past, several studies were conducted to determine the coronary dominance [Table $5 \& 6$ ]. In all studies, frequency of right dominance is more than that of left dominance and co-dominance except the study done by Fazliogullari $\mathrm{Z}$ et al. which showed the incidence of co-dominance is more than that of right dominance [Table 5]. ${ }^{[11]}$ The incidence of right dominance in the present study is similar to the findings of studies done by Allwork SP, Cavalcanti J.S. et al, Eren et al., Das H et al. and Pusala B et al [Table 5 \& 6]. ${ }^{[10,12-16]}$

In most of the studies done in the past, the incidence of left dominance is more than the incidence of co-dominance. But some studies showed the greater incidence of co-dominance over left dominance [Table $5 \& 6]^{[2,11-13,17-22]}$ The findings of a study done by Bharambe V K and Arole V U showed similar incidence of left dominance and co-dominance[Table $5] .{ }^{[23]}$ The incidence of left dominance and co-dominance is same in studies of Allwork SP, Pusala B et al, Patel S, and Priyadharshini S and Sivakumar M [Table $5 \& 6]^{[10,15,24,25]}$ The incidence of left dominance in the present study is similar to the findings of Ramanathan L et al., Bhimalli S et al, and Abuchaim D C Soares et al [Table $5 \&$ 6]. ${ }^{[19,26,27]}$ Left dominant hearts are at an increased risk of coronary heart diseases. ${ }^{[15]}$
No case of co-dominance was reported by James, Kalpana R, Anbumani TL et al, Khona P and Ashwini C., Gebhard C et al [Table $5 \& 6$ 6. ${ }^{[28-32]}$ Pusala $B$ et al., Patel S, Priyadharshini $S$ and Sivakumar $M$ and Allwork SP reported the same incidence of left and co-dominance[Table $5 \& 6]^{[15,24,25,33]}$ In the present study, the incidence of codominance was $6 \%$, which is similar to the reports of Kate G.J.R. ten et al. ${ }^{[34]}$ In the present study, Co- dominance was seen only in male subjects. Knaapen $\mathrm{M}$ et al found that the prevalence of a left dominant or codominant coronary system decreased with increasing age. ${ }^{[22]}$

Goldberg A et al hypothesized that the prognosis of patients with Acute Coronary Syndrome (ACS) with Left Dominance (LD) would be worse than that of patients with right or mixed dominance. They concluded that in patients with ACS, Left Dominance is a significant and independent predictor of increased long-term mortality. ${ }^{[35]}$ In a CT angiographic study, Eren et al found that the coronary diseases and the number and rate of coronary artery variations are significantly higher among the individuals with left dominant circulation. ${ }^{[13]}$ Kuno $\mathrm{T}$ et al. observed that among ACS patients who underwent Percutaneous Coronary Intervention (PCI), patients with left dominance had significantly worse in-hospital outcomes compared with patients with right dominance, and left dominant anatomy was an independent predictor of in-hospital mortality due to heart failure, cardiogenic shock or cardiopulmonary arrest. ${ }^{[36]}$ Murphy ES et al, found in patients of aortic stenosis with left dominance, an increased risk of perioperative myocardial infarction if there is associated obstructive coronary artery disease. Patients with left dominance have a shorter left main coronary artery than patients with right dominance. Preoperative information about the coronary arterial anatomy and extent of coronary artery disease may be helpful in planning the use of coronary perfusion and other myocardial preservation techniques during surgery in order to reduce the incidence of myocardial infarction. ${ }^{[37]}$

In cases where patients are being considered for right coronary bypasses, it is particularly important to call the attention of the surgeon to the presence of any of the anatomic variations. These variations affect the decision regarding the nature of bypasses to be constructed. Where the vessels do not conform to classical anatomic conceptions, it may be impossible, unless one is forewarned to the atypical configuration. In cases of dual supply of inter-ventricular septum, multiple stenoses might necessitate construction of two different bypasses to provide adequate vascularization. $^{[8]}$

Table 5: Comparative percentages of coronary dominance among various autopsy and cadaveric studies

\begin{tabular}{|c|c|c|c|c|c|}
\hline $\begin{array}{c}\begin{array}{c}\text { Authors and } \\
\text { of Study }\end{array} \\
\end{array}$ & Type of Study & $\begin{array}{l}\text { Population \& } \\
\text { No. of cases }\end{array}$ & Right Dominance & Left Dominance & Co-dominance \\
\hline $\begin{array}{l}\text { Nerantzis } \text { C } \\
\text { Avgoustakis D, } 1980\end{array}$ & $\begin{array}{lr}\text { Autopsy } & \text { (X-ray } \\
\text { films \& } & \text { Corrosion } \\
\text { casting) } & \end{array}$ & $\begin{array}{l}\text { Greek } \\
300\end{array}$ & 88.67 & 9.33 & 2 \\
\hline $\begin{array}{llll}\text { Kurjia } & \text { HZ } & \text { et } & \text { al, } \\
1986 & & & \\
\end{array}$ & Autopsy & Iraqi & 46 & 14 & 40 \\
\hline $\begin{array}{ll}\text { Kalpana } & \mathrm{R}, \\
2003 & \end{array}$ & Cadaveric & $\begin{array}{l}\text { South Indian } \\
100\end{array}$ & 89 & 11 & NIL \\
\hline $\begin{array}{l}\text { Abuchaim D C Soares et } \\
\text { al, } 2009\end{array}$ & Corrosion casting & $\begin{array}{l}\text { Brazilian } \\
25\end{array}$ & 72 & 20 & 8 \\
\hline Das $\mathrm{H}$ et al, & Cadaveric & East Indian (Assamese)70 & 70 & 18.57 & 11.43 \\
\hline
\end{tabular}


Tamar et al; $\mathcal{P D A}$ d Caranary Daminance

\begin{tabular}{|c|c|c|c|c|c|}
\hline Fazliogullari Z et al, 2010 & Cadaveric & $\begin{array}{l}\text { Turkish } \\
50\end{array}$ & 42 & 14 & 44 \\
\hline Bhimalli S et al, 2011 & Cadaveric & $\begin{array}{l}\text { Indian } \\
60\end{array}$ & 60 & 23.33 & 16.66 \\
\hline $\begin{array}{l}\text { Bharambe V K } \text { and } \\
\text { Arole VU., } 2013\end{array}$ & Cadaveric & $\begin{array}{ll}\begin{array}{l}\text { Western } \\
\text { (Maharashtra) 50 }\end{array} & \text { India } \\
\end{array}$ & $60-78$ & $12-24$ & $10-24$ \\
\hline $\begin{array}{l}\text { Jaishree } \mathrm{H} \text { and Ashwini H, } \\
2015\end{array}$ & Cadaveric & South Indian 76 & 83 & 14.5 & 2.5 \\
\hline Anbumani T L et al, 2016 & Cadaveric & South Indian 50 & 84 & 16 & NIL \\
\hline $\begin{array}{lrr}\text { Priyadharshini } & \text { S } & \& \\
\text { Sivakumar M, 2016 } & \\
\end{array}$ & Cadaveric & South Indian (Kerala) 50 & 84 & 8 & 8 \\
\hline Pal M et al, 2016 & Cadaveric & West Bengali 50 & 70 & 22 & 8 \\
\hline Pusala B et al., 2017 & Cadaveric & $\begin{array}{l}\text { South Indian (Telangana) } \\
80\end{array}$ & 70 & 15 & 15 \\
\hline $\begin{array}{l}\text { Khona P and Ashwini C, } \\
2018\end{array}$ & Cadaveric & $\begin{array}{l}\text { South Indian (Karnatka) } \\
100\end{array}$ & 83 & 17 & NIL \\
\hline Meshram SW, 2018 & Cadaveric & $\begin{array}{ll}\text { Western } & \text { India } \\
\text { (Maharashtra) 50 } & \\
\end{array}$ & 68 & 8 & 12 \\
\hline
\end{tabular}

Table 6: Comparative percentages of coronary dominance among various angiographic studies

\begin{tabular}{|c|c|c|c|c|c|c|c|c|}
\hline $\begin{array}{l}\text { Authors and } \\
\text { Year of Study }\end{array}$ & Type of Study & $\begin{array}{c}\text { Population \& } \\
\text { No. of cases }\end{array}$ & \multicolumn{2}{|c|}{ Right Dominance } & \multicolumn{2}{|c|}{ Left Dominance } & \multicolumn{2}{|c|}{ Co-dominance } \\
\hline Schlesinger M.J, 1940 & & & \multicolumn{2}{|l|}{48} & \multicolumn{2}{|l|}{18} & \multicolumn{2}{|l|}{34} \\
\hline James,1961 & & & \multicolumn{2}{|l|}{90} & \multicolumn{2}{|l|}{10} & \multicolumn{2}{|l|}{ NIL } \\
\hline Allwork SP, 1987 & & & \multicolumn{2}{|l|}{70} & \multicolumn{2}{|l|}{15} & \multicolumn{2}{|l|}{15} \\
\hline $\begin{array}{l}\text { Cavalcanti J S et al, } \\
1995\end{array}$ & & & \multicolumn{2}{|c|}{69.09} & \multicolumn{2}{|l|}{11.82} & \multicolumn{2}{|c|}{19.09} \\
\hline Angelini P et al, 2002 & Angiography & 1950 & \multicolumn{2}{|c|}{81.61} & \multicolumn{2}{|l|}{8.4} & \multicolumn{2}{|l|}{2.5} \\
\hline Kini $\mathbf{S}$ et al., 2007 & 64-slice CTCA & & \multicolumn{2}{|c|}{$80-85$} & \multicolumn{2}{|l|}{$15-20$} & \multicolumn{2}{|l|}{5} \\
\hline $\begin{array}{ll}\text { Patel } & \text { S, } \\
2008 & \end{array}$ & 64-slice CTCA & & \multicolumn{2}{|l|}{85} & \multicolumn{2}{|l|}{$7-8$} & \multicolumn{2}{|l|}{$7-8$} \\
\hline $\begin{array}{llll}\text { Cademartiri } & F & \text { et } & \text { al, } \\
2008 & & & \\
\end{array}$ & 64-slice CTCA & 543 & \multicolumn{2}{|l|}{86.6} & \multicolumn{2}{|l|}{9.2} & \multicolumn{2}{|l|}{4.2} \\
\hline \multirow{3}{*}{$\begin{array}{lll}\text { Eren } & \text { et al., } \\
2008 & & \end{array}$} & \multirow{3}{*}{ 16-slice CTCA } & \multirow[t]{3}{*}{325} & \multicolumn{2}{|l|}{70} & \multicolumn{2}{|l|}{12.5} & \multicolumn{2}{|l|}{17.5} \\
\hline & & & $\mathrm{M}$ & $\mathrm{F}$ & $\mathrm{M}$ & $\mathrm{F}$ & $\mathrm{M}$ & $\mathrm{F}$ \\
\hline & & & 69 & 71 & 12 & 13 & 19 & 16 \\
\hline $\begin{array}{l}\text { Kate G.J.R. ten et al, } \\
2008\end{array}$ & 64-slice CTCA & $\begin{array}{l}\text { Netherland } \\
1000\end{array}$ & 85.1 & & 8.8 & & 6.1 & \\
\hline $\begin{array}{l}\text { Vasheghani-Farahani A } \\
\text { et al, 2008 }\end{array}$ & $\begin{array}{l}\text { Coronary } \\
\text { angiography }\end{array}$ & $\begin{array}{l}\text { Irani } \\
12558\end{array}$ & 84.2 & & 10.9 & & 4.8 & \\
\hline Pınar Koşar et al, 2009 & $\begin{array}{lr}64-s l i c e & \mathrm{CT} \\
\text { coronary angiography }\end{array}$ & $\begin{array}{l}\text { Turkish } \\
700\end{array}$ & 76 & & 9.1 & & 14.8 & \\
\hline $\begin{array}{l}\text { Abdelmoneim AA } \\
\text { Abdellah et al, 2009 }\end{array}$ & Catheter angiography & $\begin{array}{l}\text { Sudanese } \\
429\end{array}$ & 77 & & 8 & & 15 & \\
\hline $\begin{array}{l}\text { Ramanathan L et al, } \\
2009\end{array}$ & Catheter angiography & $\begin{array}{l}\text { South Indian } \\
300\end{array}$ & 53.66 & & 22.33 & & 24 & \\
\hline Kevin NC et al, 2010 & CTCA & 105 & 85.7 & & 9.5 & & 4.8 & \\
\hline Mian FA et al, 2011 & Catheter angiography & $\begin{array}{l}\text { Pakistani } \\
200\end{array}$ & 60.5 & & 19.5 & & 20 & \\
\hline Knaapen M et al, 2013 & $\begin{array}{l}\text { Coronary } \\
\text { angiography }\end{array}$ & $\begin{array}{l}\text { Netherland } \\
1553\end{array}$ & 81.2 & & 9.1 & & 9.7 & \\
\hline Gebhard C et al, 2015 & CTCA & 6382 & 91 & & 9 & & NIL & \\
\hline Present study, 2011 & 64-slice CTCA & North Indian & 72 & & 22 & & 6 & \\
\hline & & 50 & $\mathrm{M}$ & $\mathrm{F}$ & $\mathrm{M}$ & $\mathrm{F}$ & $\mathrm{M}$ & $\mathrm{F}$ \\
\hline & & & 75 & 66.67 & 15.63 & 33.33 & 9.38 & NIL \\
\hline
\end{tabular}

M: Male, F: Female

\section{Conclusion}

In the present study, PDA most commonly arose from RCA and frequency of origin of PDA from LCX Ar. was more in females. There is no significant difference in the dominance pattern of coronary circulation among males and females.Posterior descending artery most commonly terminated after traversing the upper half of posterior interventricular groove and there is no significant difference in the termination pattern of PDA among males and females.

\section{References}

1. Villa AD, Sammut E, Nair A, Rajani R, Bonamini R, Chiribiri A.
Coronary artery anomalies overview: the normal and the abnormal. World J Radiol. 2016; 8(6): 537-55.

2. Schlesinger MJ. Relation of anatomic pattern to pathologic conditions of the coronary arteries. Arch Path.1940; 30: 403-415.

3. Allwork SP. Angiographic anatomy. In: Anderson R H, Becker E, editors. Cardiac anatomy. London: Churchill Livingstone; 1980

4. Dr Matt A. Morgan. Left-dominant coronary circulation [Internet]. Available from: https://www.radiopaedia.org/cases/left-dominantcoronay-circulation.

5. Kini S, Kostaki G. Bis, and Weaver L. Normal and variant coronary arterial and venous anatomy on high-resolution CT angiography. American journal of radiology. 2007; 188: 1665-1674.

6. Standring S, editor-in-chief. Gray's anatomy. The anatomical basis of clinical practice.40thed. Churchill Livingstone: Elsevier; 2008.

7. Dr Yuranga Weerakkody, Dr Craig Hacking et al. Coronary arterial dominance [Internet]. Available from https://www.radiopaedia.org/cases/coronary-arterial-dominance. 
8. David C. Levin and Harold A. Baltaxe. Angiographic demonstration of important anatomic variations of the posterior descending coronary artery. American Journal of Roentgenology. 1972; 116: 41-49.

9. Kim JH, Cha KS, Park S Y, Park T H, Kim M H, Kim Y D. Anomalous origins of the right and posterior descending coronary arteries from the left anterior descending coronary artery: unusual pattern of single coronary artery. Journal of Cardiology Cases. 2011; 3(1): e26-e28

10. Allwork S P. The anatomy of the coronary arteries. In The surgery of coronary artery disease. London: Chapman \& Hall; 1986: p.15-25.

11. Fazliogullari Z, Karabulut A K, Unver Dogan N, Uysal I I. Coronary artery variations and median artery in turkish cadaver hearts. Singapore Med J. 2010; 51(10): 775.

12. Cavalcanti JS., de Lucena OM., Pais e Melo AV Jr, Balaban G, de Andrade Oliveira CL, de Lucena OE. Anatomic variations of the coronary arteries. Arq Bras Cardiology. 1995; 65 (6): 489-492.

13. Eren, Suat, Bayram, Ednan, Fil, Fadime et al. An investigation of the association between coronary artery dominance and coronary artery variations with coronary arterial disease by multidetector computed tomographic coronary angiography. Journal of Computer Assisted Tomography. 2008; 32( 6): 929-933.

14. Das H, Das G, Das DC, Talukdar K. A study of coronary dominance in the population of Assam. Journal of Anatomical Society of India. 2010; 59(2): 187-191.

15. Pusala B, Venkateshwer MR. Termination and dominance of coronary arteries: on Telangana population. Int J Anat Res. 2017; 5(2.1): 373540.

16. Pal M, Saha D, Chatterjee M. A cadaveric study of coronary artery dominance on West Bengal population. Indian Journal of Basic and Applied Medical Research. 2016: 5(3), 18 - 24.

17. Kurjia HZ, Chaudhry MS. Coronary artery variation in a native Iraqi population. Catheter Cardiovascular Diagnosis. 1986; 12(6): 386-90.

18. Abdelmoneim AA Abdellah, Ahmed SA Elsayed, Mohamed A Hassan. Angiographic coronary artery anatomy in the Sudan heart centre. Khartoum Medical Journal. 2009; 2(1): 162 -164.

19. Ramanathan L, Shetty P, Nayak SR, Krishnamurthy A, Chettiar GK, Chockalingam A. Origin of the sinoatrial and atrioventricular nodal arteries in South indians: An Angiographic Study. Arq Bras Cardiol. 2009; 92(5): 314-319.

20. Koşar P, Ergun E, Öztürk C, Koşar U. Anatomic variations and anomalies of the coronary arteries: 64-slice angiographic appearance. Journal of the Turkish Society of Radiology. 2009; 15(4): 275-283.

21. Meshram SW. The study of coronary artery dominance and its clinical significance in central India population. Indian Journal of Applied Research. 2018; -8(3): 5-7.

22. Knaapen M, Koch AH, Koch C, Koch KT, Li X, Peter C. van Rooij et al. Prevalence of left and balanced coronary arterial dominance decreases with increasing age of patients at autopsy. A Postmortem Coronary Angiograms Study. Cardiovascular Pathology. 2013; 22: 4953.

23. Bharambe V K and Arole V U. A study of coronary dominance. National Journal of Basic Medical Sciences. 2013; 3(3): 178-183.

24. Patel S. Normal and anomalous anatomy of the coronary arteries. Semin Roentgenology. 2008; 43:100-112.

25. Priyadharshini. S and Sivakumar. M. A study of coronary arterial dominance pattern. Int J Anat Res. 2016; 4(3): 2817-21.

26. Bhimalli S, Dixit D, Siddibhavi $M$ and Shirol VS. A study of variations in coronary arterial system in cadaveric human heart. World Journal of Science and Technology. 2011; 1(5): 30-35.

27. Abuchaim D C Soares, Spera C A, Faraco DL, Ribas Filho JM,
Malafaia. O. Coronary dominance patterns in the human heart investigated by corrosion casting. Rev Bras Cir Cardiovasc. 2009; 24(4): 514-518.

28. James T.N. Anatomy of the coronary arteries. New York: 1961.Paul B. Hoeber; 12-150.

29. Kalpana R. A Study on Principal Branches of Coronary Arteries in Humans. Journal of the Anatomical Society of India. 2003; 52(2):712.

30. Anbumani T L, Christus D, Thamarai SA, Anthony AS. An anatomical study on the coronary arteries and their variations. Int $\mathrm{J}$ Anat Res. 2016; 4(1): 2114-18.

31. Khona $\mathrm{P}$ and Ashwini C. A study of coronary dominance in population of North Karnataka. Int J Anat Res. 2018; 6(1.3): 5030-33.

32. Gebhard C, Tobias AF, Stehli J, Gransar H, Daniel SB, Matthew JB et al. Coronary dominance and prognosis in patients undergoing coronary computed tomographic angiography: results from the confirm (Coronary CT Angiography Evaluation For Clinical Outcomes: An International Multicenter). European Heart JournalCardiovascular Imaging. 2015; 16: 853-862

33. Allwork SP. The applied anatomy of the arterial blood supply to the heart in man. J. Anat. 1987; 153: 1-16.

34. Kate GJR ten, Weustink AC, Feyter PJ de. Coronary artery anomalies detected by MSCT-coronary angiography in the adult. Netherlands Heart Journal. 2008; 16(11).

35. Goldberg A, Southern DA, Galbraith PD, Traboulsi M, Knudtson ML, Ghali WA. Coronary dominance and prognosis of patients with acute coronary syndrome. Am Heart J. 2007; 154(6): 1116-22.

36. Kuno T, Numasawa Y, Miyata H, Takahashi T, Sueyoshi K, Takahiro $\mathrm{O}$ et al. Impact of coronary dominance on in-hospital outcomes after percutaneous coronary intervention in patients with acute coronary syndrome. PLoS ONE. 2013; 8(8): e72672. doi:10.1371/journal.pone.0072672

37. Murphy ES, Rösch J and Rahimtoola SH. Frequency and significance of coronary arterial dominance in isolated aortic stenosis. The American Journal of Cardiology. 1977; 39(4): 505-509

38. Nerantzis C and Avgoustakis D. An S- Shaped Atrial Artery Supplying the Sinus Node Area. Chest. 1980; 78: 274-278.

39. Jaishree H and Ashwini H. Study of coronary dominance in the population of hyderabad karnataka region. Int J Cur Res Rev. 2015; $7(20): 6-8$

40. Angelini P, Velasco JA, Flamm S. Coronary anomalies incidence, pathophysiology, and clinical relevance. Circulation. 2002; 105:24492454.

41. Cademartiri F, La Grutta L, Malagò R, Alberghina F, Meijboom WB, Pugliese $\mathrm{F}$ et al. Prevalence of anatomical variants and coronary anomalies in 543 consecutive patients studied with 64-slice CT coronary angiography. Journal of European Radiology. 2008; 18(4): 781-91

42. Vasheghani-Farahani A, Kassaian SE, Yaminisharif A, Davoodi G, Salarifar M, Amirzadegan A et al. The association between coronary arterial dominancy and extent of coronary artery disease in angiography and paraclinical studies. Clinical Anatomy. 2008; 21: 519-23

43. Kevin NC, Scott RH, Adam TF, Brinjikji W, Araoz P, Samuel JA et al. Anatomic assessment of the bifurcation of the left main coronary artery using multidetector computed tomography. Surg Radiol Anat. 2010; 32(10): 903-9.

44. Mian FA, Malik SN, Ismail M, Khan IS, Kachlu AR, Rehman M et al. Coronary artery dominance: what pattern exists in Pakistani population? Ann. Pak. Inst. Med. Sci. 2011; 7(1): 3-5 3

Copyright: (๑) the author(s), publisher. Academia Anatomica International is an Official Publication of "Society for Health Care \& Research Development". It is an open-access article distributed under the terms of the Creative Commons Attribution Non-Commercial License, which permits unrestricted non-commercial use, distribution, and reproduction in any medium, provided the original work is properly cited.

How to cite this article: Tomar S, Manik P, Sharma PK, Kumar M. PDA (Posterior Descending Artery) \& Coronary Dominance-A MDCT Coronary Angiographic Analysis of Anatomic Variations and Clinical Importance. Acad. Anat. Int. 2018;4(2):21-27.

DOI: dx.doi.org/10.21276/aanat.2018.4.2.7

Source of Support: Nil, Conflict of Interest: None declared. 